Check for updates

Cite this: J. Mater. Chem. A, 2020, 8 , 13340

Received 14th April 2020

Accepted 20th June 2020

DOI: 10.1039/d0ta04031b

rsc.li/materials-a

\section{Nickel confined in 2D earth-abundant oxide layers for highly efficient and durable oxygen evolution catalysts $\uparrow$}

\author{
Yayun Pu, ab Matthew J. Lawrence, (DD a Veronica Celorrio, (D) ${ }^{c}$ Qi Wang, ${ }^{d}$ Meng Gu, ${ }^{d}$ \\ Zongzhao Sun, ${ }^{\mathrm{b}}$ Leonardo Agudo Jácome, ${ }^{\mathrm{e}}$ Andrea E. Russell, (iD ${ }^{\mathrm{f}}$ Limin Huang (D)*b \\ and Paramaconi Rodriguez (iD *a
}

\begin{abstract}
Low cost, high-efficiency catalysts towards water splitting are urgently required to fulfil the increasing demand for energy. In this work, low-loading (<20 wt\%) Ni-confined in layered metal oxide anode catalysts (birnessite and lepidocrocite titanate) have been synthesized by facile ion exchange methodology and subjected to systematic electrochemical studies. It was found that $\mathrm{Ni}$-intercalated on $\mathrm{K}$-rich birnessite ( $\mathrm{Ni}-\mathrm{KMO}$ ) presents an onset overpotential ( $\left.\eta_{\text {onset }}\right)$ as low as $100 \mathrm{mV}$ and overpotential at $10 \mathrm{~mA} \mathrm{~cm}{ }^{-2}\left(\eta_{10}\right)$ of $206 \mathrm{mV}$ in $\mathrm{pH}=14$ electrolyte. By combining electrochemical methods and $\mathrm{X}$-ray absorption and emission spectroscopies (XAS and XES), we demonstrate Ni sites are the active sites for OER catalysis and that the $\mathrm{Mn}^{3+}$ sites facilitate $\mathrm{Ni}$ intercalation during the ion-exchange process, but display no observable contribution towards OER activity. The effect of the $\mathrm{pH}$ and the nature of the supporting electrolyte on the electrochemical performance was also evaluated.
\end{abstract}

\section{Introduction}

The availability of a carbon neutral sustainable energy supply has become remarkably urgent in recent decades. Electrochemical water splitting, using renewable energy sources, offers an attractive route to chemical energy storage. However, one of the current limitations for the implementation of this technology is related to the inefficiency of the oxygen evolution reaction (OER) catalyst. ${ }^{1-3}$ Metal oxide catalysts based on precious metals such as $\mathrm{IrO}_{2}$ and $\mathrm{RuO}_{2}$ have been commonly used. However, their high cost and low abundance is a significant hindrance. Therefore, in the last decade there has been an enormous effort from the scientific community towards the

${ }^{a}$ School of Chemistry, University of Birmingham, Edgbaston, Birmingham B15 2TT, UK. E-mail: P.B.Rodriguez@bham.ac.uk

${ }^{b}$ Department of Chemistry, Southern University of Science and Technology, No. 1088 Xueyuan Blvd, Shenzhen, Guangdong 518055, China. E-mail: huanglm@sustech. edu.cn

'Diamond Light Source Ltd, Diamond House, Harwell Campus, Didcot, OX11 ODE, UK ${ }^{d}$ Department of Materials Science and Engineering, Southern University of Science and Technology, No. 1088 Xueyuan Blvd, Shenzhen, Guangdong 518055, China

${ }^{e}$ Bundesanstalt für Materialforschung und-prüfung (BAM), Department Materials Engineering, Unter Den Eichen 87, 12205 Berlin, Germany

${ }^{f}$ School of Chemistry, University of Southampton, Highfield, Southampton, SO17 1BJ, $U K$

$\dagger$ Electronic supplementary information (ESI) available: Full description of the experimental methods, XRD patterns, calculation of charge integration, Tafel plots, long-term durability experiments and XAS fitting analysis. See DOI: 10.1039/d0ta04031b development of inexpensive and earth-abundant OER catalysts. ${ }^{4-9}$

Amongst a number of different catalysts reported, layered metal oxide/hydroxide nanoparticles of earth abundant elements are of particular interest in electrochemical water splitting. Compared with the more typically employed $\mathrm{RuO}_{2}$ and $\mathrm{IrO}_{2}$ electrocatalysts, the $\mathrm{M}$-based oxides/hydroxides $(\mathrm{M}=\mathrm{Ni}$, $\mathrm{Co}, \mathrm{Fe}, \mathrm{Mn}$ ), as well as their oxyhydroxide and double metal hydroxides, are attractive as they possess extremely high surface areas, providing a large number of exposed active sites, and enhanced electronic conductivity after exfoliation. ${ }^{10-14}$ Such layered oxide/hydroxides consist of $\mathrm{MO}_{6}$ host layers stabilized by charge-balancing ions accommodated into the interlayer spacing. The $\mathrm{M}-\mathrm{O}$ layers fulfill both roles of skeleton, for architecture, and active sites, leading to insufficient atomic efficiency. To enhance the performance and efficiency of these catalysts previous reports have presented the preparation of ultrathin two-dimensional (2D) nanosheets, aiming at the exposure of more active sites. ${ }^{5,8}$ Improving the atomic efficiency of active atoms, such as $\mathrm{Ru}$, Ir, $\mathrm{Ni}$ or $\mathrm{Co}$, is economically attractive for large-scale industrial applications. ${ }^{15,16}$ In the literature a variety of strategies have been implemented, including synthesis of nanoclusters and even single atoms anchored on carbon-based and metal oxides-based supports. ${ }^{17,18}$ Although, to date, very little attention has been dedicated to the ions in the channels formed between the 2D layered oxide structures. Catalytic ions in between the layers can be arranged in-plane and immobilized by the opposite charge of the $2 \mathrm{D}$ host layer (Fig. 1a). ${ }^{19}$ The $2 \mathrm{D}$ channels fundamentally act 
as ideal electrochemical nanoreactors providing ample interlayer spacing for free transportation of reactants and products and confinement of the under-coordinated active atoms. ${ }^{20,40}$ Previous work by Thenuwara et al., show that Ni-intercalated on birnessite is a potential catalyst for the OER at $\mathrm{pH}=14 .^{\mathbf{4 0}}$

An important parameter affecting the electrochemical performance of catalysts during the OER is the pH. It is well known that the $\mathrm{pH}$ and composition of the electrolyte have a significant impact on the performance and durability of the catalyst during the OER. Establishing correlations between $\mathrm{pH}$ and measured voltammetric profiles facilitates the deduction of the active sites for OER and the evolution of adsorption/ desorption processes and species on the surface. Takashima et al. reported that the instability of active $\mathrm{Mn}^{3+}$ at $\mathrm{pH}<9$ is the key factor in the observed poor activity of $\delta-\mathrm{MnO}_{2}$ toward the
OER, which requires additional potential to electrochemically oxidize $\mathrm{Mn}^{2+}$ to $\mathrm{Mn}^{3+} \cdot{ }^{21}$ Koper's group proposed the surface deprotonation mechanism of NiOOH during OER catalysis based on the $\mathrm{pH}$ sensitivity observed. ${ }^{22}$ With that in mind, the catalytic activity of confined catalysts in layered structures, where reactant diffusion is rigorously restricted, would be strongly affected by the $\mathrm{pH}$ dominated deprotonation kinetics.

The manuscript describes the synthesis and full characterization of $\mathrm{Ni}$ ions confined to the inter-layer space in 2D layered MnO nanoparticles prepared via a facile ion exchange strategy using $\mathrm{NiCl}_{2}$ as a precursor. The characterization of the materials using XAS/XES provided comprehensive understanding of the role of $\mathrm{Mn}^{3+}$ in the $\mathrm{Ni}$ intercalation process, the oxidation state of the species and the different $\mathrm{Ni}$ coordination/structures obtained for Ni-KMO and Ni-HMO. We demonstrate the catalytic

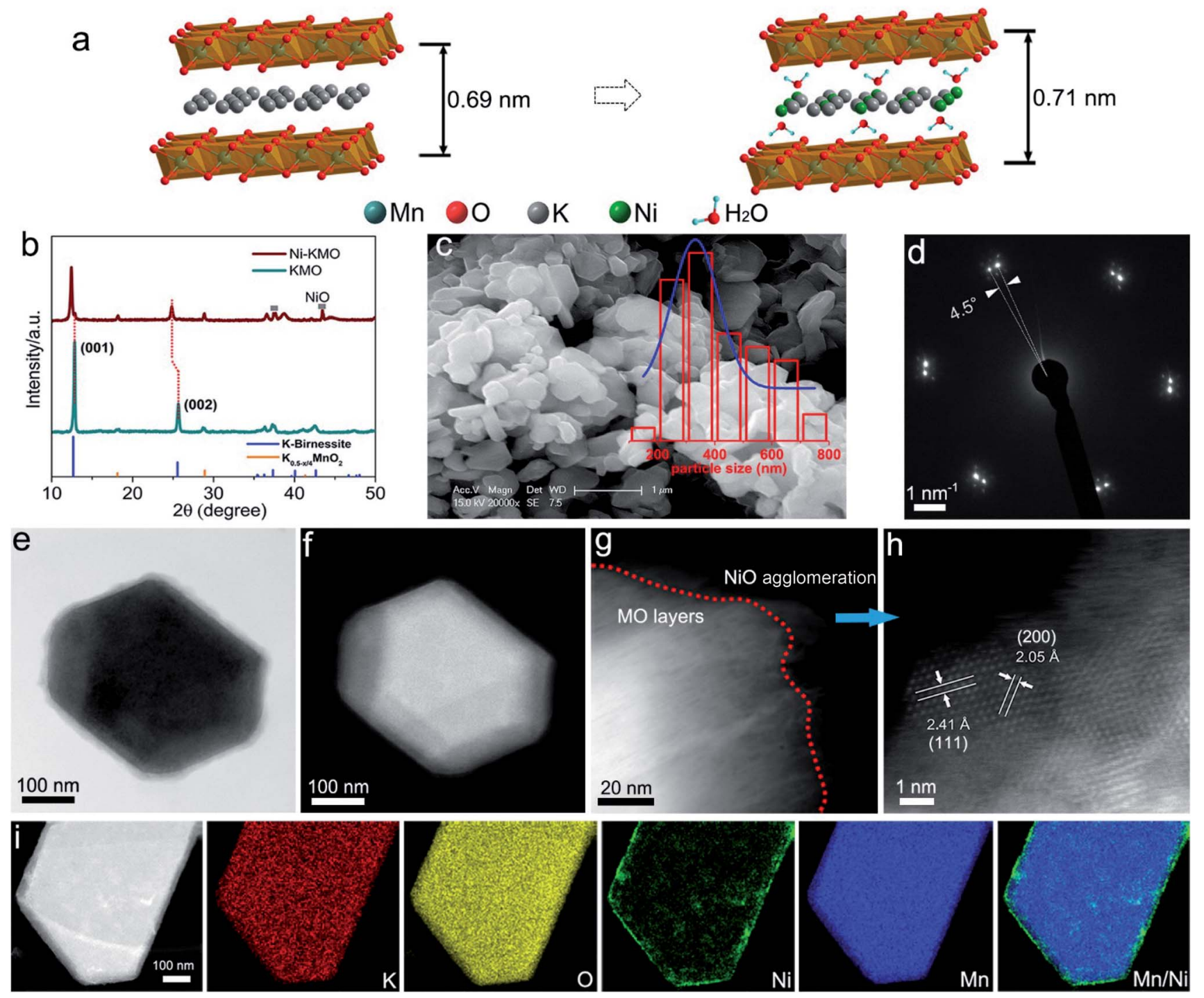

Fig. 1 (a) Schematic illustration of the impact of Ni intercalation into layered K-birnessite manganese oxide. (b) X-ray diffraction patterns of Ni$\mathrm{KMO}$ and pristine KMO. (c) SE-SEM image of Ni-KMO nanoplates. The particle size distribution histogram is inset. (f) SAD diffraction pattern (ZA = $[001]_{\mathrm{Ni}-K M O}$ ) of particle in (e). (e) Bright field (BF) and (f) HAADF-STEM images of Ni-KMO nanoparticle seen along [001] zone axis (ZA). HAADFSTEM images ( $g$ ), and (h) enlarged Ni agglomeration at the edge of a Ni KMO nanoplate. (i) HAADF-STEM image of single Ni-KMO nanoplate with corresponding EDS elemental mapping. 
activity towards the OER and the long term durability of the catalyst. In addition, we also present the reaction mechanism for the OER on the Ni-confined catalyst based on an exhaustive study of the catalyst under different conditions, e.g. $\mathrm{pH}$ and scan rate.

\section{Results and discussion}

\subsection{Characterization of Ni-confined KMO}

Ni-exchanged $\mathrm{K}_{0.45} \mathrm{MnO}_{2}$ (Ni-KMO) was prepared by mixing $\mathrm{K}$ rich birnessite $\left(\mathrm{K}_{0.45} \mathrm{MnO}_{2}\right)$ and $\mathrm{NiCl}_{2}$ solution at ambient temperature, as described in the Experimental section (ESI $\dagger$ ). Fig. $1 \mathrm{~b}$ presents the XRD patterns of the as-prepared KMO and after Ni exchange. From the XRD pattern it was determined that the K-birnessite possessed a layered structure with an interlayer spacing of $0.69 \mathrm{~nm}$ (AMCSD 0001302). ${ }^{23}$ The same layered structure was retained after the $\mathrm{Ni}$ exchange process, with XRF measurements suggesting that $\mathrm{Ni}$ cations partially replaced $\mathrm{K}$ ions in the interlayer spacing (Table 1). Such intercalation resulted in the enlargement of the interlayer distances (001) and (002) along the $c$ axis, demonstrated by the decrease in $2 \theta$ values for those diffraction signals at $2 \theta=12.43^{\circ}$ and $24.84^{\circ}$. The SEM (Fig. 1c) and STEM images (Fig. 1d, e and g-i) of Ni-KMO show plate-like nanoparticles with facets with dimensions between 300-400 nm with near-identical morphology to that of KMO (Fig. S1 $\dagger$ ). The bright field (BF) and high angle annular darkfield (HAADF) images in Fig. 1e and $f$ show a single nanoparticle comprising stacked layers of KMO. In Fig. 1d, the selected area diffraction (SAD) pattern shows a splitting of the reflections, which can be interpreted as an in-plane rotation of $4.5^{\circ}$ (marked at the Ni-KMO (110) reflection) between two sets of layers in the nanoparticle. The HAADF-STEM image in Fig. $1 \mathrm{~h}$ suggests that the $\mathrm{Mn}-\mathrm{O}$ framework retained a layered structure, which is consistent with the XRD results. In addition to the $\mathrm{Ni}$ atoms inserted into the interlayer channels, aggregation of $\mathrm{Ni}$ at the edges of the nanoplate crystals, generating a few nanometer-thick region, is observed in the HAADF images and EDS elemental maps (Fig. $1 \mathrm{i}$ (contrast the Ni and Mn HAADF images) and Fig. S2 and $\mathrm{S} 3 \dagger$ ). The additional XRD signals observed for Ni-KMO at $37.4^{\circ}$ and $43.4^{\circ}$, which can be assigned to (111) and (200) of NiO (JCPDS 73-1519), are in agreement with STEM results.

\subsection{XAS analysis}

The adsorption energies of ${ }^{*} \mathrm{OH}$ and $\mathrm{O} *$ are predominantly dependent on the electronic configuration of the $\mathrm{Ni}$ surfaces. ${ }^{24}$ Therefore, the local environment of the Ni sites and associated species determine the corresponding electrochemical activity of these materials. X-ray absorption spectroscopy (XAS) was implemented to determine the oxidation state and coordination environment of $\mathrm{Ni}$ and the Mn-oxide host structure and to enable correlation of these parameters with the underlying OER performance of Ni-KMO. The characteristic XANES spectra of metallic Mn, standard Mn-oxide compounds with oxidation states spanning the range $\mathrm{Mn}^{+2}$ to $\mathrm{Mn}^{+4}$ and the synthesized X$\mathrm{K}(\mathrm{H}) \mathrm{MO}$ nanoplates (where $\mathrm{X}=\mathrm{H}$ or $\mathrm{Ni}$ ) are presented in Fig. $2 \mathrm{a}$.

The edge positions, determined by the maximum of the first derivative, for $\mathrm{Mn}$ foil, $\mathrm{MnO}, \mathrm{Mn}_{3} \mathrm{O}_{4}, \mathrm{Mn}_{2} \mathrm{O}_{3}$ and $\mathrm{MnO}_{2}$ were observed at 6539.0, 6544.2, 6546.7, 6547.7 and $6552.5 \mathrm{eV}$, respectively, in agreement with existing literature values..$^{25-27}$ The measured edge positions for KMO, $\mathrm{H}(\mathrm{K}) \mathrm{MO}$ and Ni-KMO and NiHMO were 6549.3, 6550.3, 6549.6 and $6552.0 \mathrm{eV}$, respectively. The normalised absorption pre-edge features of the manganese oxide derivatives and relevant $\mathrm{Mn}$ K-edge reference oxide compounds are presented in Fig. S4. $\dagger$ An increase in pre-edge peak energy is observed with an increase in Mn oxidation state (Fig. S4a†). The nature of the pre-edge features of the spectra at the Mn K-edge suggest that there is a contribution from $\mathrm{Mn}^{2+}, \mathrm{Mn}^{3+}$ and $\mathrm{Mn}^{4+}$ to the overall structure and the intermediate mean Mn oxidation state is between +3 and +4 . Thus, X-ray emission spectroscopy (XES) was employed to obtain more accurate Mn oxidation state information. The measured XES spectra and corresponding fits, a function of the sum contributions of the standard $\mathrm{Mn}^{n+}$ oxide compounds, are presented in Fig. S5. $\dagger$ The mean Mn oxidation state of pristine KMO was determined as +3.9 (Table S1†). A decrease in mean oxidation state was observed upon cation exchange with both $\mathrm{H}^{+}$and $\mathrm{Ni}^{2+}$, with the greatest decrease observed for $\mathrm{H}(\mathrm{K}) \mathrm{MO}$. The fraction of $\mathrm{Mn}^{4+}$ is effectively the same for Ni-KMO and KMO, while the $\mathrm{Mn}^{3+}$ fraction decreases upon Niexchange. This suggests that $\mathrm{Ni}^{2+}$ intercalation is more favorable at those $\mathrm{Mn}^{3+}$ sites, which are commonly accompanied by defects that contribute to the overall negative charge of Mn-O layers. ${ }^{8}$ The defects with higher Gibbs energy favor the ion exchange reaction of $\mathrm{K}$ with Ni. The concentration of $\mathrm{Mn}^{3+}$ increases significantly in $\mathrm{H}(\mathrm{K}) \mathrm{MO}$ relative to $\mathrm{KMO}$, thus more Ni cations were intercalated into Ni-HMO, as confirmed by the XRF analysis (Table 1).

The characteristic XANES spectra measured of metallic Ni, Ni-oxide reference compound, Ni-KMO, Ni-HTO and Ni-HMO are presented in Fig. 2b. The edge position of the Ni foil and $\mathrm{NiO}$ reference were determined as $8333.0 \mathrm{eV}$ and $8345.2 \mathrm{eV}$, respectively. The absorption edges of Ni-KMO, Ni-HTO and NiHMO were determined as 8345.3, 8345.9 and $8346.0 \mathrm{eV}$ respectively, suggesting a $\mathrm{Ni}$ oxidation state of +2 . For Ni-KMO the XANES spectrum appears identical to that of the NiO reference, indicative of the presence of $\mathrm{NiO}$ structure in $\mathrm{Ni}$ -

Table 1 XRF results of $\mathrm{Ni}-\mathrm{KMO}, \mathrm{Ni}-\mathrm{H}(\mathrm{K}) \mathrm{MO}$ and $\mathrm{Ni}-\mathrm{HTO}^{a}$

\begin{tabular}{lcll}
\hline Samples & $\mathrm{Ni}(\mathrm{at} \%)$ & $\mathrm{K}(\mathrm{at} \%)$ & $\mathrm{Mn}(\mathrm{at} \%)$ \\
\hline $\mathrm{Ni}_{0.16} \mathrm{~K}_{0.2} \mathrm{MnO}_{2} \cdot 0.7 \mathrm{H}_{2} \mathrm{O}$ & $11.67 \pm 0.18$ & $14.46 \pm 0.2$ & $73.87 \pm 0.37$ \\
$\mathrm{Ni}_{0.33} \mathrm{~K}_{0.04} \mathrm{MnO}_{2} \cdot 0.9 \mathrm{H}_{2} \mathrm{O}$ & $24.1 \pm 0.4$ & $2.69 \pm 0.09$ & $71.26 \pm 0.5$ \\
$\mathrm{Ni}_{0.033} \mathrm{Ti}_{0.91} \mathrm{O}_{2} \cdot 0.6 \mathrm{H}_{2} \mathrm{O}$ & $3.60 \pm 0.07$ & - & -
\end{tabular}

${ }^{a}$ TGA was performed to determine the water amount in Ni-intercalated layered metal oxides (Fig. S24). 

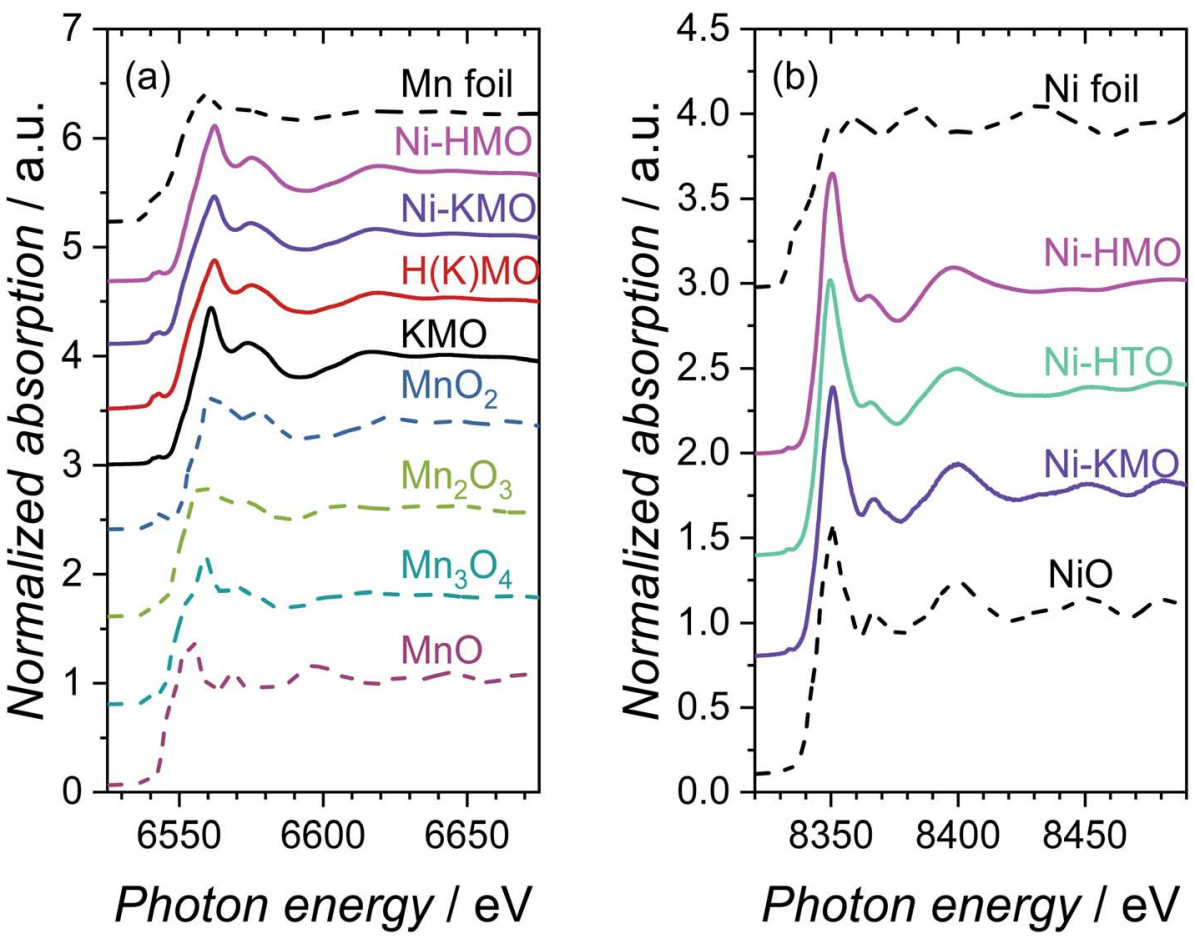

Fig. 2 Normalized XANES spectra measured at the (a) Mn K-edge and (b) Ni K-edge for KMO, H(K)MO, Ni-KMO, Ni-HMO and Ni-HTO catalysts, in addition to relevant standard oxide compounds and metal foils. References, represented by dashed lines, are shown for comparison.

KMO. While slightly different spectrum of Ni-HMO compared to Ni-KMO suggesting a different $\mathrm{Ni}^{2+}$ structure, as confirmed by the fitted EXAFS results below. There are no significant differences in pre-edge features observed at the Ni K-edge (Fig. S4b†).
The Mn K-edge EXAFS Fourier transforms (FTs) of the synthesised KMO, H(K)MO, Ni-KMO and Ni-HMO nanosheets and reference samples are presented in Fig. 3a. The first peak at $\sim 1.5 \AA$ (not phase shift corrected) is due to the Mn-O scattering and the second peak at $\sim 2.5 \AA$ (not phase shift corrected) is due
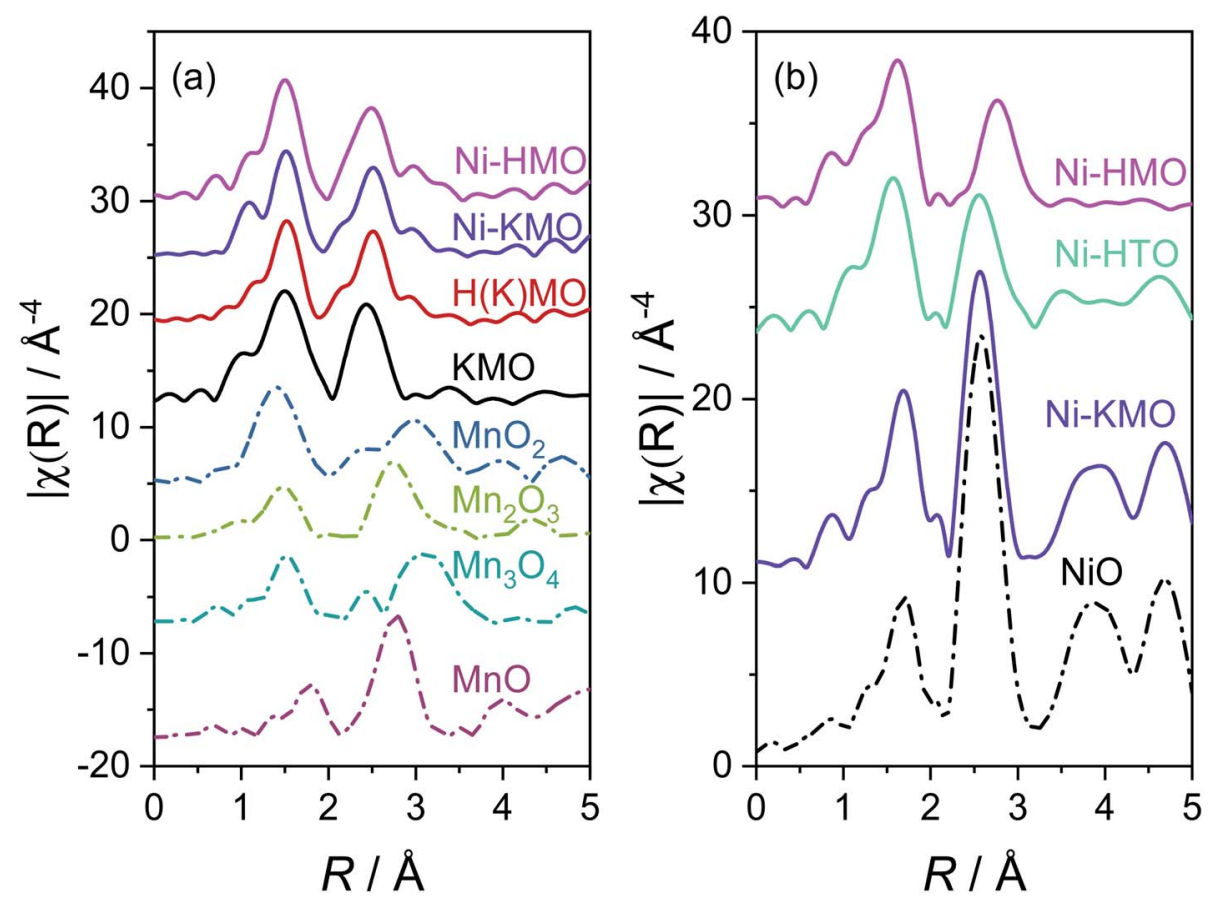

Fig. 3 EXAFS FTs of $k^{3} \chi(k)$ functions for $\mathrm{KMO}, \mathrm{H}(\mathrm{K}) \mathrm{MO}, \mathrm{Ni}-\mathrm{KMO}, \mathrm{Ni}-\mathrm{HMO}$ and $\mathrm{Ni}-\mathrm{HMO}$ nanosheets and standard oxide reference compounds at (a) $\mathrm{Mn} \mathrm{K}$-edge and (b) Ni K-edge. References are shown for comparison. 
to $\mathrm{Mn}-\mathrm{Mn} / \mathrm{Mn}-\mathrm{Ni}$ scattering (Tables S2, S3 and Fig. S6†). The two Mn scattering distances are generated by the two distinct $\mathrm{Mn}$ birnessite lattice sites: edges and face-centers. The Ni Kedge EXAFS FT of Ni-KMO is near-identical to the NiO reference compound. The first shell coordination at $\sim 1.7 \AA$ (not phase shift corrected) corresponds to $\mathrm{Ni}-\mathrm{O}$ whilst the second shell coordination at $\sim 2.6 \AA$ (not phase shift corrected) corresponds to Ni-Ni scattering (Table S4 $\dagger$ ). The relative amplitude of the second shell peak for Ni-KMO compared to NiO suggests that the former comprises NiO nanoparticles. This is not the case for Ni-HTO and Ni-HMO, where the relative amplitude of the second shell peak differs from that of NiO, suggesting the formation of a different structure (Tables S5 and S7 $\dagger$ ).

In summary, the ex situ XAS/XES results clarify the importance of $\mathrm{Mn}^{3+}$ on the Ni-exchange intercalation. The Ni-content in each of the samples is proportional to the concentrations $\mathrm{Mn}^{3+}$ sites. For all the prepared samples, $\mathrm{Ni}$ is present in the oxidation state $(+2)$, but different $\mathrm{Ni}$ coordination/structures were obtained for Ni-KMO and Ni-HMO.

\section{Electrochemical performance of $\mathrm{Ni}$-confined catalyst on $\mathrm{KMO}$}

\subsection{Evaluation of the electrochemical activity and durability}

The catalytic activity of $\mathrm{Ni}-\mathrm{KMO}$ was evaluated over the $\mathrm{pH}$ range 8-14, to provide both assessment of the activity of the electrocatalysts for the OER and enable deeper understanding of the mechanism behind this activity. Fig. $4 \mathrm{a}-\mathrm{c}$ show the stable $i R$-corrected voltammetric profiles of the Ni-KMO catalyst as a function of the $\mathrm{pH}$, with the voltammograms shown being those obtained after 30 consecutive cycles; the evolution of the curves over the 30 scans is presented in Fig. S10. $\dagger$ Current densities are reported as $\mathrm{mA} \mathrm{cm} \mathrm{cm}^{-2}$ normalized by the geometric area of the electrode. As can be seen, the OER onset overpotential $\left(\eta_{\text {onset }}\right)$ increases with decreasing $\mathrm{pH}$, from $130 \mathrm{mV}$ at pH 14 to $220 \mathrm{mV}$ at pH 12. (Note that all voltammetric responses are reported $v s$. RHE and, thus, differences are not attributable to changes to the potential of the reference electrode.). At the same time, the overpotential at $10 \mathrm{~mA} \mathrm{~cm}^{-2}\left(\eta_{10}\right)$ was $240 \mathrm{mV}$ at $\mathrm{pH} 14$, which is significantly smaller than the $\eta_{10}=1090 \mathrm{mV}$ observed at $\mathrm{pH} 12$. The marginal difference in measured $\eta_{\text {onset }}$ and sharp contrast at $\eta_{10}$ confirm the lower reaction rate of the OER at lower $\mathrm{pH}$ due to the lower concentration and availability of $\mathrm{OH}^{-}$. Fig. 4b summarizes the observed trends.

The redox activity of the confined Ni clusters is evident in the voltammograms as a quasi-reversible peak in the region between 1.2-1.5 V was observed at $\mathrm{pH} 14$ and 12 (Fig. 4c). This peak has previously been ascribed to the $\mathrm{Ni}^{2+} \leftrightarrow \mathrm{Ni}^{3+}$ couple of $\mathrm{Ni}$ based catalysts. ${ }^{15,22,28,29}$ Interestingly, at $\mathrm{pH}=14$ the oxidation peak of $\mathrm{Ni}^{2+} \rightarrow \mathrm{Ni}^{3+}$ appears at $1.24 \mathrm{~V}$, which is significantly more cathodic relative to previous reports in the literature ( $1.4 \mathrm{~V}$ vs. RHE on carbon electrode). This unusual cathodic
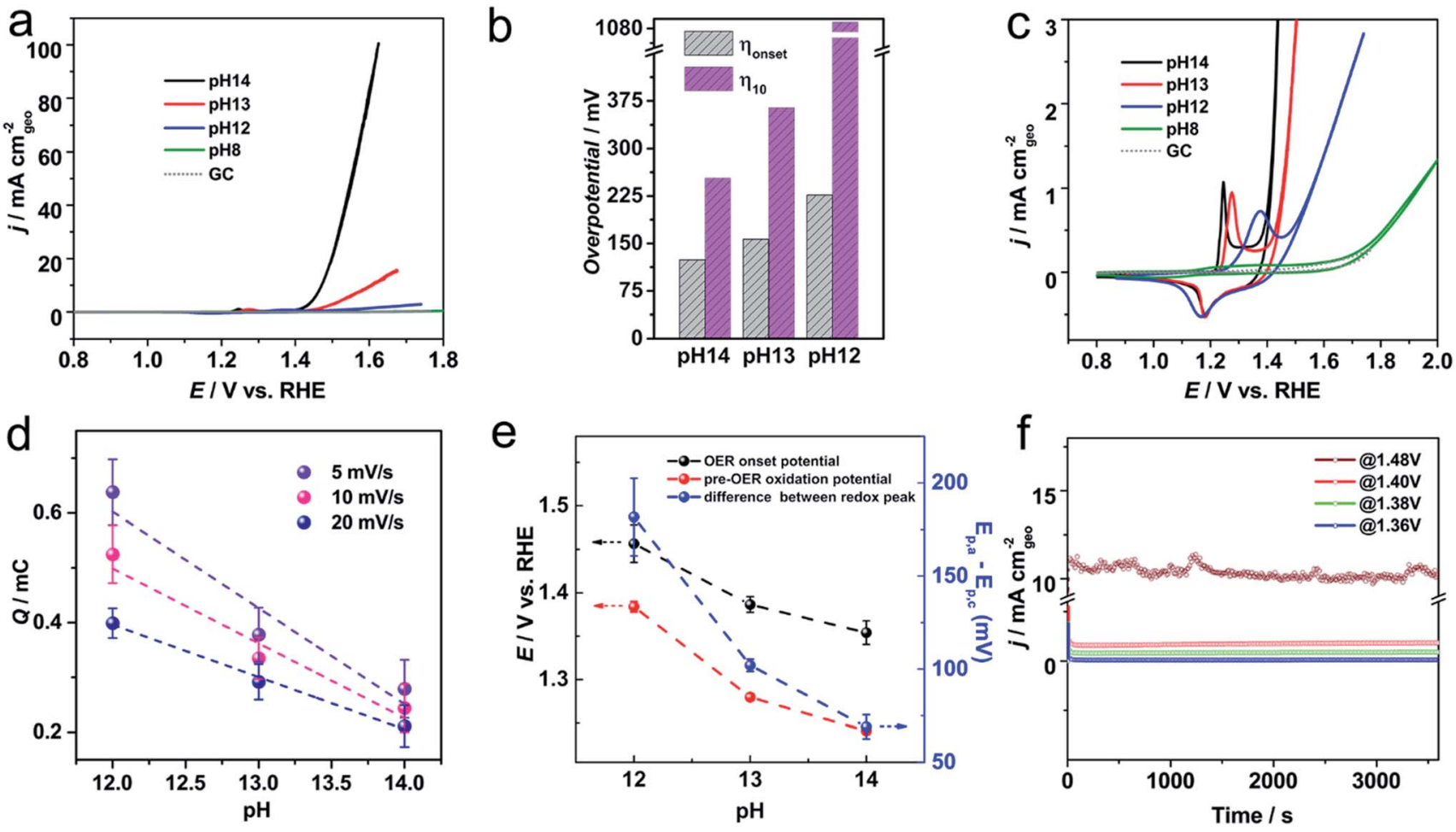

Fig. 4 (a) Stable cyclic voltammograms of $\mathrm{Ni}-\mathrm{KMO}$ at various $\mathrm{pHs}$ after 30 consecutive scans in $\mathrm{NaOH}$ electrolyte, with scan rate of $20 \mathrm{mV} \mathrm{s}^{-1}$. The profile of the glassy carbon (GC) support is included for comparison. All the curves are $i R$-corrected. (b) The onset overpotential ( $\eta_{\text {onset }}$ ) and overpotential at $j=10 \mathrm{~mA} \mathrm{~cm}{ }^{-2}\left(\eta_{10}\right)$ obtained from (a). (c) Enlarged region showing the $\mathrm{Ni}^{2+} \rightarrow \mathrm{Ni}^{3+}$ redox peaks at various pHs. (d) Integrated charge of $\mathrm{Ni}^{2+/ 3+}$ oxidation peak as a function of $\mathrm{pH}$ at various scan rates. (e) OER onset potential, pre-OER oxidation peak potential and $\mathrm{Ni}^{2+/ 3+}$ $\Delta E$ variation with $\mathrm{pH}$. (f) Chronoamperometry profiles of $\mathrm{Ni}-\mathrm{KMO}$ at $\mathrm{pH}=14$ at various applied potentials as indicated in the figure. 
shift of oxidation peak to $1.24 \mathrm{~V}$ is beneficial for subsequent catalytic oxygen evolution. As seen in Fig. 4c, a direct relationship between the position of the $\mathrm{Ni}^{2+} \rightarrow \mathrm{Ni}^{3+}$ oxidation peak on the Ni-KMO and the OER onset potential was observed as a function of $\mathrm{pH}$. Increasing the $\mathrm{pH}$ of the solution from 12 to 14 results in the shift of the $\mathrm{Ni}^{2+} \rightarrow \mathrm{Ni}^{3+}$ oxidation peak together with a shift of the onset potential of OER towards less positive potentials. This is a clear indicator that the $\mathrm{Ni}^{3+}$ are active sites for the OER. Moreover, the correlation between redox peaks and OER activity over multiple cycles is shown in Fig. S10. $\dagger$ At any one $\mathrm{pH}$, the $\mathrm{Ni}^{2+} \rightarrow \mathrm{Ni}^{3+}$ oxidation peak shifts cathodically and the OER current density increases as a function of the number of cycles, confirming the role of $\mathrm{Ni}^{2+} \rightarrow \mathrm{Ni}^{3+}$ transformation on OER catalysis. This behavior is in agreement with previous work that established the relationship between the peak position of the redox couple on $\mathrm{Ni}-\mathrm{Fe}(\mathrm{OOH})$ and the OER catalytic activity. ${ }^{30}$

Since the OER catalytic activity is directly correlated to the nature of the Ni centers, understanding the redox peak of the $\mathrm{Ni}$ in the cyclic voltammograms may contribute to greater understanding of the reaction mechanism as well as in the development of better catalyst. Voltammetric profiles of the $\mathrm{Ni}^{2+} / \mathrm{Ni}^{3+}$ redox peaks were recorded at different $\mathrm{pHs}$ (Fig. $\mathrm{S} 11 \dagger$ ). At $\mathrm{pH}=$ 14 the presence of two discrete processes, Ox1/Re1 and Ox2/Re2, were observed. Previous reports assigned the process Ox1 $\leftrightarrow$ Re1 to the phase transition $\alpha-\mathrm{Ni}(\mathrm{OH})_{2} / \gamma-\mathrm{NiOOH}$, while the process labelled Ox2 $\leftrightarrow$ Re2 has been associated with the transition of $\beta-\mathrm{Ni}(\mathrm{OH})_{2}$ to the active phase $\beta-\mathrm{NiOOH} .{ }^{31,32} \mathrm{~A}$ schematic illustration of the phase transitions is presented in Fig. S12. $\dagger$ When the $\mathrm{pH}$ is decreased to 13 , only one oxidation peak is observed (Ox1) and the peak labelled Re 2 shifts towards more positive potentials and its current density decreases (Fig. S11 $\dagger$ ). At $\mathrm{pH}=12$, the $\mathrm{Re} 2$ peak is not observable and only the redox peak Ox1/Re1 is visible. The absence of the $\beta-\mathrm{NiOOH}$ transformation at $\mathrm{pH}=12$ was accompanied by a significant reduction in measured OER activity.

To explore the underlying mechanism, we thoroughly examined the relationship between the $\mathrm{Ni}^{2+} / \mathrm{Ni}^{3+}$ redox peaks and the scan rates. The linear relationship between peak current density and scan rate at $\mathrm{pH}=14$ was indicative that the surface reaction kinetics were dominated by charge transfer steps, whereas the linear relationship between peak current density and the square root of the scan rate at $\mathrm{pH}=12$ was indicative that the diffusion limitation was the dominating factor (Fig. S13†).

The charge associated with the redox peaks as a function of the $\mathrm{pH}$ is also shown in Fig. $4 \mathrm{~d}$ and $\mathrm{S} 14 . \dagger$ As can be seen, opposite to the literature, ${ }^{30}$ the charge associated to the redox peak of $\mathrm{Ni}^{2+} / \mathrm{Ni}^{3+}$ increases as the $\mathrm{pH}$ decreases. We further explore this phenomenon by analyzing the charges of the redox peak at $\mathrm{pH}=12$ and $\mathrm{pH}=14$ as a function of the number of cycles. Fig. S15† shows the comparison between the charge of the redox peaks of the 1st scan and 30th scan for the different pHs. The first observation is that slightly larger charges are observed at $\mathrm{pH}=14$ and $\mathrm{pH}=13$. As can be seen, the charge of the oxidation peak increases after electrochemical cycling across the $\mathrm{pH}$ range explored. However, the increase of the charge of the redox peak is significantly larger at $\mathrm{pH}=12$ and after 30 cycles. Charge of the redox peak at $\mathrm{pH}=12(399 \mu \mathrm{C})$ is 1.89 -fold that of the same peak at $\mathrm{pH}=14(211 \mu \mathrm{C})$. According to the discussion above, and the XAS results (Section 2.2) the Niclusters intercalated between the KMO layers must undergo an "activation process", which is attributed to a phase transformation of the Ni oxide species. While at $\mathrm{pH}=14$, Ni sites with $\mathrm{OH}^{-}$adsorption are fully transformed into the $\beta-\mathrm{NiOOH}$ active form, at $\mathrm{pH}=12$ most of the catalyst is only transformed into the $\gamma-\mathrm{NiOOH}$ phase. Considering that the oxidation state of the $\beta-\mathrm{NiOOH}$ is +3 and the $\gamma-\mathrm{NiOOH}$ is $\sim 3.7$ (Fig. S15 $\dagger$ ), the transformation from $\mathrm{Ni}^{2+}$ to $\gamma-\mathrm{NiOOH}$ requires $\sim 1.7$ fold more charges than that to the $\beta-\mathrm{NiOOH}$. Therefore, our results suggest that at $\mathrm{pH}=14$ the active phase for the OER is the $\beta$ $\mathrm{NiOOH}$ and at $\mathrm{pH}=12$, the active phase for the OER is the $\gamma$ $\mathrm{NiOOH}$. The unique structure of the Ni confined in 2D layer structure with flexibly adjustable interlayer spacing gives rise to such phenomenon.

In order to obtain more information on the reaction mechanism, Tafel analysis of the OER curves at different pHs was performed. Note that all voltammograms were $i R$ corrected prior to the Tafel analysis. It has been previously proposed that the overall mechanism of OER catalysis on Ni sites in alkaline media involve four on-electron-transfer steps (eqn (1)-(4)). ${ }^{15,33}$ The Tafel plots for the OER on Ni-KMO at different pHs are presented in Fig. S16. $\dagger$ The Tafel slope, at $\mathrm{pH}=14$, is $60 \mathrm{mV}$ $\mathrm{dec}^{-1}$ suggesting that the rate-determining step (RDS) was the deprotonation of adsorbed hydroxyl species (eqn (2)), in agreement with previous works on Ni hydroxide/oxide catalyst. ${ }^{34}$ On the other hand, a Tafel slope of $232 \mathrm{mV} \mathrm{dec}^{-1}$ was obtained at $\mathrm{pH} 12$, suggesting that the RDS at lower $\mathrm{pH}$ was the adsorption of $\mathrm{OH}^{-}$species (eqn (1)). This can be rationalized by consideration of the nature of Ni sites. A higher concentration gradient is required to promote the transport of the $\mathrm{OH}^{-}$species from electrolyte through the channels of the layered oxide structure to the confined Ni nanoreactor sites. This diffusion-dependent process gives rise to the significant difference in OER activity observed for Ni-KMO with varying pHs.

$$
\begin{gathered}
\mathrm{Ni}^{*}+\mathrm{OH}^{-} \rightarrow \mathrm{Ni}^{*} \mathrm{OH}+\mathrm{e}^{-} \\
\mathrm{Ni}^{*} \mathrm{OH}+\mathrm{OH}^{-} \rightarrow \mathrm{Ni}^{*} \mathrm{O}+\mathrm{H}_{2} \mathrm{O}+\mathrm{e}^{-} \\
\mathrm{Ni}{ }^{*} \mathrm{O}+\mathrm{OH}^{-} \rightarrow \mathrm{Ni}^{*} \mathrm{OOH}+\mathrm{e}^{-} \\
\mathrm{Ni}^{*} \mathrm{OOH}+\mathrm{OH}^{-} \rightarrow \mathrm{Ni}^{*}+\mathrm{O}_{2}+\mathrm{H}_{2} \mathrm{O}+\mathrm{e}^{-}
\end{gathered}
$$

The evaluation of the electrochemical performance of a catalyst should not only be based on its catalytic activity but also on the durability of the catalyst. Long-term stability of the Ni-KMO was recorded at $\mathrm{pH}=14$ via chronoamperometry at various applied potentials (Fig. 2f). As can be seen in Fig. 2f, the current density during the OER remained stable over $1 \mathrm{~h}$ of electrolysis at different relevant potentials. In order to gain insight into the structural and compositional stability of the catalyst, SEM and HAADF-EDS images of the Ni-KMO catalyst were collected after $10 \mathrm{~h}$ (Fig. S17 $\dagger$ ). Interestingly, no significant changes in the morphology or the element distribution of the 


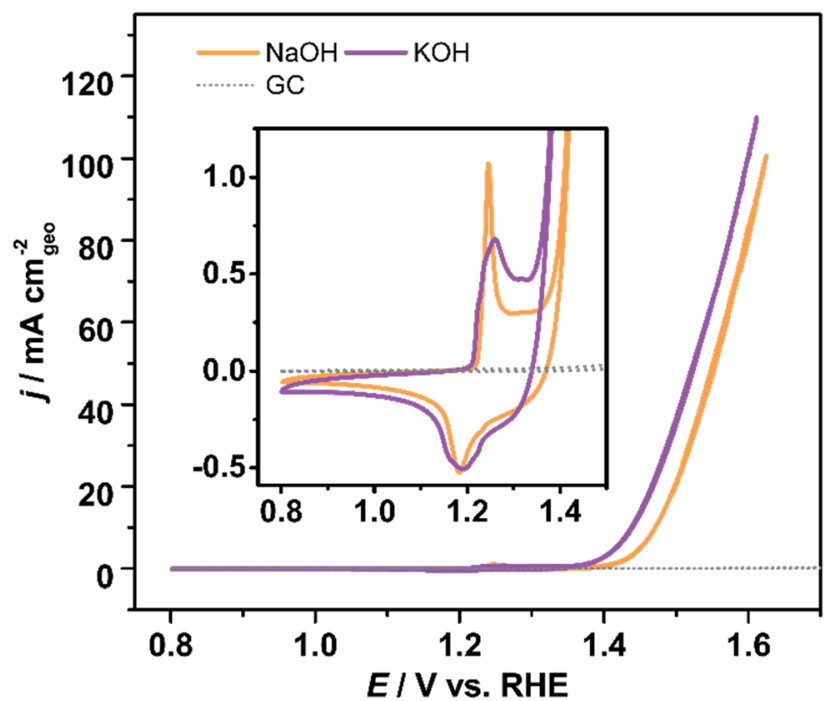

Fig. 5 Voltammetric profiles of $\mathrm{Ni}-\mathrm{KMO}$ in $1 \mathrm{M} \mathrm{KOH}$ and $\mathrm{NaOH}$ electrolyte, as indicated in the figure, inset is the enlarged redox features. Glassy carbon shown for comparison. Scan rate $v=20 \mathrm{mV} \mathrm{s}^{-1}$.

catalyst were detected confirming the excellent stability of the catalyst after $10 \mathrm{~h}$ of electrolysis. A comparison of the long term stability, up to $23 \mathrm{~h}$ electrolysis in $1 \mathrm{M} \mathrm{NaOH}$, of the $\mathrm{Ni}-\mathrm{KMO}$ at $1.48 \mathrm{~V}$ and Ni-HTO at $1.51 \mathrm{~V}$ shows stable current densities for catalysis with current densities over $10 \mathrm{~mA} \mathrm{~cm}{ }^{-2}$ (Fig. S23†).

\subsection{Effect of the cations on the OER catalytic activity}

Previous works have also demonstrated that in addition to the $\mathrm{pH}$, the nature of the electrolyte cation also affects the observed activity and selectivity of electrochemical processes, especially in alkaline media. ${ }^{35,36}$ We investigated the effect of $\mathrm{K}^{+}$and $\mathrm{Na}^{+}$ cations on the electrochemical activity of Ni-KMO towards the OER (Fig. 5). As can be seen, although a slightly different shape of the $\mathrm{Ni}^{2+} \rightarrow \mathrm{Ni}^{3+}$ redox peaks was observed, the charges for the $\mathrm{Ni}^{2+} / \mathrm{Ni}^{3+}$ redox peaks are almost identical, $0.261 \mathrm{mC}$ in $\mathrm{NaOH}$ and $0.263 \mathrm{mC}$ in $\mathrm{KOH}$ respectively. Ni-KMO presents lower $\eta_{\text {onset }}$ and $\eta_{10}$ for the OER in $\mathrm{KOH}\left(\eta_{\text {onset }}=100 \mathrm{mV}\right.$ and $\eta_{10}=$ $206 \mathrm{mV})$ relative to the respective values in $\mathrm{NaOH}\left(\eta_{\text {onset }}=\right.$ $130 \mathrm{mV}$ and $\eta_{10}=240 \mathrm{mV}$ ). It has been previously demonstrated, that the nature of the cations affects the catalytic activity of the OER and the ORR. In particular, those reports indicate that potassium enhances the catalytic activity. ${ }^{37-39}$ This effect has been associated to the non-covalent interaction between $\mathrm{K}^{+}\left(\mathrm{H}_{2} \mathrm{O}\right)_{x} / \mathrm{Na}^{+}\left(\mathrm{H}_{2} \mathrm{O}\right)_{x}$ clusters and the active Nioxygenated species at the surface $\mathrm{Ni}-\mathrm{OH}^{*}, \mathrm{Ni}-\mathrm{O}^{*}, \mathrm{Ni}-\mathrm{OOH}^{*}$. Fig. 5 shows that the onset of the $\mathrm{Ni}^{2+} / \mathrm{Ni}^{3+}$ oxidation reaction is independent of the cation present in the electrolyte $(\mathrm{KOH}$ or $\mathrm{NaOH}$ ) which indicates similar adsorption reaction of $\mathrm{OH}^{-}$on Ni sites. On the other hand, at slightly more positive potentials a slight cathodic shift of OER onset in $\mathrm{KOH}$ suggests that the subsequent deprotonation step is favorable in $\mathrm{KOH}$. Suntivich et al. suggested that charged $\mathrm{K}^{+}\left(\mathrm{H}_{2} \mathrm{O}\right)_{x} / \mathrm{Na}^{+}\left(\mathrm{H}_{2} \mathrm{O}\right)_{x}$ clusters would
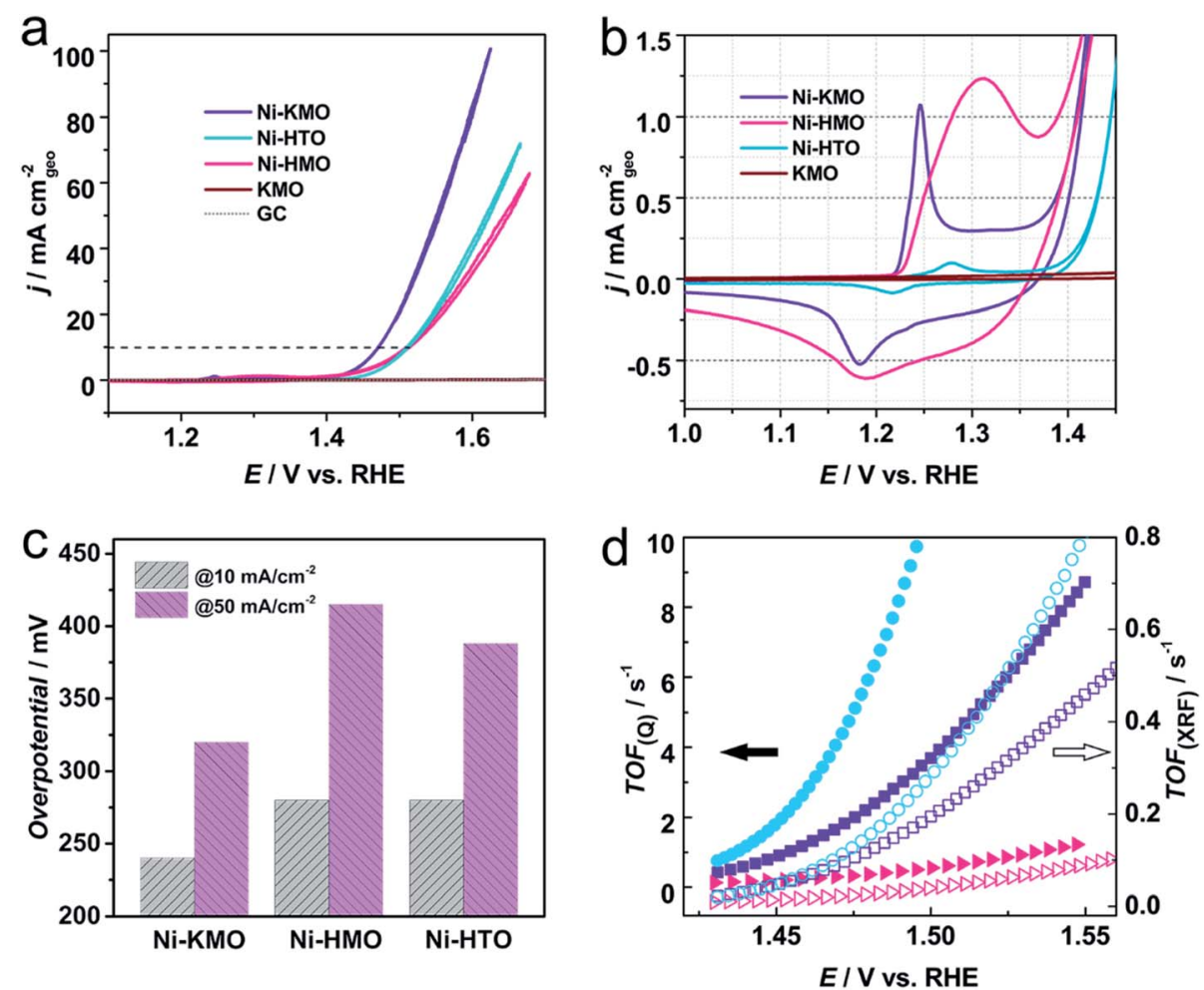

Fig. 6 (a) iR-corrected voltammetric profiles of $\mathrm{Ni}-\mathrm{KMO}, \mathrm{Ni}-\mathrm{HMO}$ and $\mathrm{Ni}-\mathrm{HTO}$ after 30 consecutive scans at $\mathrm{pH}=14$, in $1 \mathrm{M} \mathrm{NaOH}$ at $20 \mathrm{mV} \mathrm{s}^{-1}$. The evolution of the voltammograms as function of the number of scans can be found in Fig. S22. $\dagger$ (b) Enlarged region showing the $\mathrm{Ni}^{2+} \rightarrow \mathrm{Ni}^{3+}$ redox peaks and OER onset. (c) $\eta_{50}$ and $\eta_{10}$ obtained from (a). (d) TOF as a function of potential calculated using the content of $\mathrm{Ni}$ content on $\mathrm{Ni}$ $\mathrm{KMO}$ (square symbol), $\mathrm{Ni}-\mathrm{HMO}$ (triangle symbol) and $\mathrm{Ni}-\mathrm{HTO}$ (circle symbol) determined by the $\mathrm{Ni}^{+2} / \mathrm{Ni}^{+3}$ redox charge (solid symbols) and the XRF (empty symbols). 
Table 2 Summary of electrochemical data of $\mathrm{Ni}-\mathrm{KMO}, \mathrm{Ni}-\mathrm{HMO}, \mathrm{Ni}-\mathrm{HTO}$

\begin{tabular}{|c|c|c|c|}
\hline & $\mathrm{Ni}_{0.16} \mathrm{~K}_{0.2} \mathrm{MnO}_{2} \cdot 0.7 \mathrm{H}_{2} \mathrm{O}$ & $\mathrm{Ni}_{0.33} \mathrm{~K}_{0.04} \mathrm{MnO}_{2} \cdot 0.9 \mathrm{H}_{2} \mathrm{O}$ & $\mathrm{Ni}_{0.033} \mathrm{Ti}_{0.91} \mathrm{O}_{2} \cdot 0.6 \mathrm{H}_{2} \mathrm{O}$ \\
\hline$\eta_{10} / \mathrm{mV}$ & 240 & 280 & 280 \\
\hline Integration charge $/ \mathrm{mC}$ & 0.278 & 0.743 & 0.0342 \\
\hline Tafel slope $/ \mathrm{mV} \mathrm{dec}^{-1}$ & 60 & 113 & 50 \\
\hline Ni content $[\mathrm{XRF}] / \mathrm{wt} \%$ & 8 & 16 & 2 \\
\hline$j_{\mathrm{mss}}$ at $\eta=240 \mathrm{mV} / \mathrm{A} \mathrm{g}_{\mathrm{Ni}}{ }^{-1}$ & 602 & 140 & 710 \\
\hline
\end{tabular}

modify the energy of M-oxygenated species, thus altering their stability. ${ }^{37}$

\subsection{Investigation of the coordination of active $\mathrm{Ni}$ on the catalytic activity}

In order to further investigate the specific role of $\mathrm{Ni}$ coordination in the performance of the catalyst, Ni-exchanged $\mathrm{HMnO}_{2}$ (Ni-HMO) and Ni-exchanged $\mathrm{HTi}_{0.91} \mathrm{O}_{2}$ (Ni-HTO) were prepared and evaluated towards the OER. Both materials, HMO and HTO, present the same layered structure (Fig. S18 $\dagger$ ), therefore any observable differences in the catalytic activity would suggest differences in the interaction between the $\mathrm{Ni}$ and species such as $\mathrm{Mn} / \mathrm{Ti}$ and $\mathrm{K} / \mathrm{H}_{2} \mathrm{O}$ around. Both Ni-HMO and Ni-HTO catalysts display notable OER activity (Fig. 6a) in comparison with the pristine HMO and HTO (Fig. S19†). As can be seen on Table $\mathrm{S} 2, \uparrow \mathrm{Ni}-\mathrm{KMO}$ shows the greatest OER catalytic activity $\left(\eta_{10}=240\right.$ $\mathrm{mV}$ ) of the three Ni-exchanged layered oxide catalysts in regard to geometrical activity. Despite the remarkable difference of $\mathrm{Ni}$ redox peaks for the 3 catalysts, the OER $\eta_{\text {onset }}$ values are nearly identical, indicating that confined $\mathrm{Ni}$ is truly the active component in the observed activity of Ni-exchanged HMO and HTO. Tafel slopes of three Ni confined samples are shown in Fig. S20. $\dagger$ Ni-HTO with $50 \mathrm{mV} \mathrm{dec}{ }^{-1}$ is smaller than Ni-KMO (60 $\mathrm{mV} \mathrm{dec}^{-1}$ ) and Ni-HMO (113 $\left.\mathrm{mV} \mathrm{dec}^{-1}\right)$. These data suggest that the chemical deprotonation process is the RDS for both Ni-HTO and Ni-KMO, whilst for Ni-HMO it is the adsorption of $\mathrm{OH}^{-}$. To obtain further information on the nature of the differences in the shape of the redox peaks and the catalytic activity, the Ni content in each of the catalysts was determined by XRF (Table 2). It was found that Ni-HMO had the greatest $\mathrm{Ni}$ loading (16 wt\%), followed by Ni-KMO (8 wt\%) and Ni-HTO ( $2 \mathrm{wt} \%$ ). Therefore, the differences in the shape of the redox peaks could be attributed to the differences in Ni loading and coordination, but the larger catalytic activity of the Ni-KMO could not be directly correlated to the Ni loading. This implies that $\mathrm{Ni}$ coordination plays the predominant role in water catalysis. This assumption is in line with the previous work by Thenuwara et al., which suggested that highly ordered water molecules lower the potential barrier that facilitate the OER. ${ }^{40}$

So far we have demonstrated that the Ni sites solely give rise to the observed OER activity of the Ni-confined layered metal oxide catalysts, thus, the Ni content allows us to determine the turnover frequency (TOF) of the catalyst, a key indicator of the intrinsic activity of a catalyst. However, two possible strategies can be adopted in this case. The TOF was determined using the total Ni content obtained from XRF measurements $\left(\mathrm{TOF}_{\mathrm{XRF}}\right)$ and by use of the wt $\%$ Ni determined by the charge of $\mathrm{Ni}^{2+} / \mathrm{Ni}^{3+}$ redox peak $\left(\mathrm{TOF}_{\mathrm{Q}}\right)$, as previously demonstrated by Nakagawa ${ }^{\mathbf{4 1}}$ and Chen $^{42}$ (Fig. 6d). As shown in Fig. 6d, whilst the two methods give different absolute values of the TOF, the trend Ni$\mathrm{HTO}>\mathrm{Ni}-\mathrm{KMO}>\mathrm{Ni}-\mathrm{HMO}$ is the same. Interestingly, despite the results above indicating that the Ni-KMO had the larger catalytic activity per geometrical surface area, Ni-HTO displays better TOF values (Table 2), indicating that it possesses the highest active atom efficiency. Determination of the \% $\mathrm{Ni}$ from the integrated charges and XRF measurements both strongly support our claim of low-loading of active catalysts for OER catalysis. For example, as the XRF result is overall evaluation of $\mathrm{Ni}$ content in catalyst, TOF calculation based on XRF display the lower limitation. $2 \mathrm{wt} \% \mathrm{Ni}$ in Ni-HTO shows a TOF $\mathrm{XRF}_{\mathrm{X}}$ of 0.1090
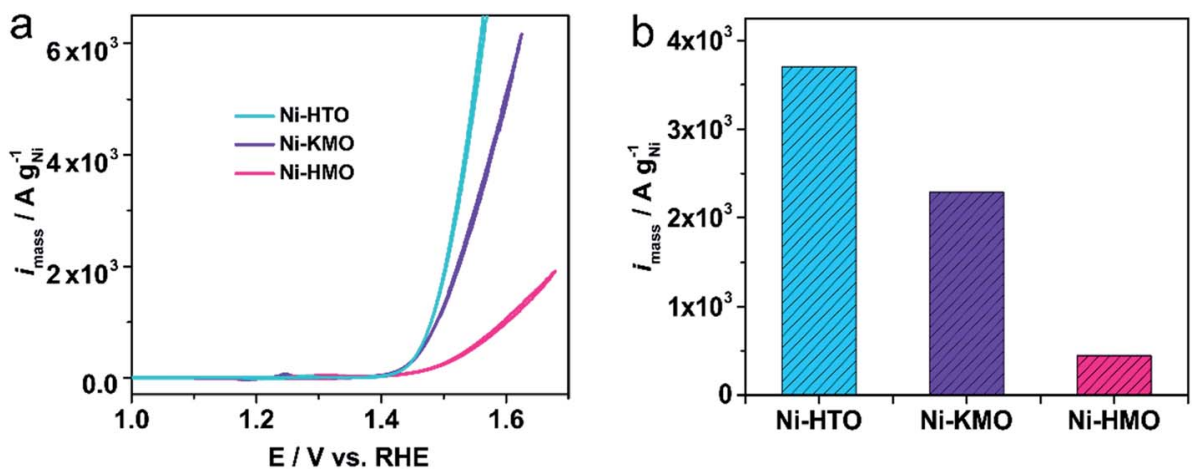

Fig. 7 (a) Voltammetric mass activity of $\mathrm{Ni}-\mathrm{KMO}, \mathrm{Ni}-\mathrm{HMO}$, and $\mathrm{Ni}-\mathrm{HTO}$ in $1 \mathrm{M} \mathrm{NaOH}$. Scan rate $v=20 \mathrm{mV} \mathrm{s}^{-1}$, (b) corresponding activity at $1.53 \mathrm{~V}$ vs. RHE. 
$\pm 0.0067 \mathrm{~s}^{-1}$ at $1.47 \mathrm{~V} v s$. RHE. While the $\mathrm{TOF}_{\mathrm{Q}}$ of Ni-HTO is 4.22 $\pm 0.05 \mathrm{~s}^{-1}$ based on integrated charge, which is an order of magnitude higher than $\mathrm{TOF}_{\mathrm{XRF}}$ (Fig. S21†).

The mass activities of our ion-exchanged catalysts in Fig. 7 are compared with other Ni-based catalysts previously reported in the literature, including a variety of Ni structures (Ni foam, self-supported $\mathrm{NiOOH}$ nanocatalysts) and shown in Table S5. $\dagger$ $\mathrm{Ni}-\mathrm{KMO}$ and Ni-HMO were found to have the largest mass activities by a factor of 4 or more. The mass activities of these $2 \mathrm{D}$ Ti-O and Mn-O Ni catalysts surpasses the state-of-the-art Nibased catalysts, such as NiV-LDH $\left(144 \mathrm{~g}_{\mathrm{Ni}}{ }^{-1} \text { @)300 mV }\right)^{43}$ or single $\mathrm{Au}$ atoms anchored on $\mathrm{NiFe}-\mathrm{LDH}\left(117 \mathrm{~g}_{\mathrm{Ni}}{ }^{-1}\right.$ @280 $\left.\mathrm{mV}\right){ }^{44}$

\section{Conclusion}

This work described the preparation and characterization of highly active OER catalysts based on the facile ion-exchange of $\mathrm{Ni}$ atoms into the $2 \mathrm{D}$ birnessite and lepidocrocite titanate structures. A direct correlation between the Ni redox peaks and the OER activity was demonstrated. After the evaluation of different catalysts as a function of the Ni content it was found that Ni-KMO and $\mathrm{Ni}-\mathrm{HTO}$ show excellent mass activity of $602 \mathrm{~A} \mathrm{~g}_{\mathrm{Ni}}{ }^{-1}$ and $710 \mathrm{~A}$ $\mathrm{g}_{\mathrm{Ni}}{ }^{-1}$ at overpotential of $240 \mathrm{mV}$, respectively. Ni-HTO shows a 6fold increase in catalytic activity per mass of $\mathrm{Ni}$ in comparison with the state-of-the-art Ni-based nanocatalysts (Au@Ni $\mathrm{Ni}_{7 / 8} \mathrm{Fe}_{1 / 8}$ $\mathrm{LDH}) .{ }^{44}$ By evaluating the electrochemical performance at varying pHs in $\mathrm{NaOH}$, it was found that the catalytic activity was enhanced at higher $\mathrm{pH}$ and in the presence of $\mathrm{K}$ cations, $\eta_{\text {onset }}=$ $100 \mathrm{mV}$ and $\eta_{10}=206 \mathrm{mV}$ were obtained in comparison with those in the presence of Na cations $\left(\eta_{\text {onset }}=130 \mathrm{mV}, \eta_{10}=240\right.$ $\mathrm{mV}$ ). The intercalation mechanism and oxidation state of $\mathrm{Ni}$ and Mn have been explored by the XAS technique. Our results demonstrate that $\mathrm{Ni}$ intercalation occurs at the $\mathrm{Mn}^{3+}$ sites by reducing $\mathrm{Mn}^{3+}$ to $\mathrm{Mn}^{2+}$. As mentioned above, the ex situ XAS/XES results show that the Ni-content in each of the samples is proportional to the concentrations $\mathrm{Mn}^{3+}$ sites. Even though $\mathrm{Ni}$ is present in the +2 oxidation state for all the samples, the $\mathrm{Ni}$ coordination/structures obtained for Ni-KMO and Ni-HMO were different. We associate the differences in OER activity to the differences in coordination/structures between $\mathrm{Ni}-\mathrm{KMO}$ and $\mathrm{Ni}$ HMO.

It was also demonstrated that while the intercalated $\mathrm{Ni}$ is the active site for oxygen evolution reaction, $\mathrm{Mn}$ sites do not contribute to the OER. Thus, the evaluation of intrinsic activity, such as TOFs and mass activity, by using the Ni content offers reliable results.

In brief, highly efficient catalysts with $\mathrm{Ni}$ confined in $2 \mathrm{D}$ layered metal oxides towards OER have been synthesized by ion exchange reactions. Our synthesis protocol provides evidence for the broader applicability of our employed methodology to other layered metal oxide structures and to compositions other than manganese oxides.

\section{Author contributions}

Y. P., P. R. and L. H. conceived the experiments. All the electrochemical experiments, XRD, XRF, SEM, TGA characterization and analyses were performed by Y. P. XANES and EXAFS characterization and analyses were performed by M. J. L. and V. C. XES measurements were collected and analyzed by V. C. and A. E. R. Low magnification HAADF- and BF-STEM, and SAD characterization were performed by L. A. J. High resolution HAADFSTEM and EDX analyses were performed by Q. W., Z. S. and M. G. All authors contributed to the analysis of the results, discussion, writing and revision of the manuscript. All authors have given approval to the final version of the manuscript.

\section{Conflicts of interest}

There are no conflicts to declare.

\section{Acknowledgements}

This work was financially supported by Southern University of Science and Technology (SUSTech) start fund through Shenzhen Peacock Talent program, Guangdong Innovative and Entrepreneurial Research Team Program (No. 2016ZT06N532), Guangdong Provincial Key Laboratory of Materials for Electric Power (2018B030322001) and Shenzhen Clean Energy Research Institute (CERI-KY-2019-003). P. R. acknowledges the University of Birmingham for financial support through the Birmingham fellowship program. This work was also supported by the Pico Center at SUSTech that receives support from Presidential fund and Development and Reform Commission of Shenzhen Municipality. The authors wish to acknowledge the Diamond Light Source for provision of beamtime (SP21659 and SP19850).

\section{References}

$1 \mathrm{~J}$. Kibsgaard and I. Chorkendorff, Considerations for the scaling-up of water splitting catalysts, Nat. Energy, 2019, 4(6), 430-433.

2 C. Wei, R. R. Rao, J. Peng, B. Huang, I. E. Stephens, M. Risch, Z. J. Xu and Y. Shao-Horn, Recommended Practices and Benchmark Activity for Hydrogen and Oxygen Electrocatalysis in Water Splitting and Fuel Cells, Adv. Mater., 2019, 1806296.

3 F. Song, L. Bai, A. Moysiadou, S. Lee, C. Hu, L. Liardet and $\mathrm{X}$. $\mathrm{Hu}$, Transition metal oxides as electrocatalysts for the oxygen evolution reaction in alkaline solutions: an application-inspired renaissance, J. Am. Chem. Soc., 2018, 140(25), 7748-7759.

4 M. P. Browne, Z. Sofer and M. Pumera, Layered and two dimensional metal oxides for electrochemical energy conversion, Energy Environ. Sci., 2019, 12(1), 41-58.

$5 \mathrm{~W}$. Zhang and K. Zhou, Ultrathin Two-Dimensional Nanostructured Materials for Highly Efficient Water Oxidation, Small, 2017, 13(32), 1700806.

6 R. Subbaraman, D. Tripkovic, K.-C. Chang, D. Strmcnik, A. P. Paulikas, P. Hirunsit, M. Chan, J. Greeley, V. Stamenkovic and N. M. Markovic, Trends in activity for the water electrolyser reactions on $3 \mathrm{~d}$ M (Ni, Co, Fe, Mn) hydr(oxy) oxide catalysts, Nat. Mater., 2012, 11(6), 550. 
7 M. S. Burke, M. G. Kast, L. Trotochaud, A. M. Smith and S. W. Boettcher, Cobalt-iron (oxy) hydroxide oxygen evolution electrocatalysts: the role of structure and composition on activity, stability, and mechanism, J. Am. Chem. Soc., 2015, 137(10), 3638-3648.

8 Y. Zhao, C. Chang, F. Teng, Y. Zhao, G. Chen, R. Shi, G. I. Waterhouse, W. Huang and T. Zhang, DefectEngineered Ultrathin $\delta$-MnO2 Nanosheet Arrays as Bifunctional Electrodes for Efficient Overall Water Splitting, Adv. Energy Mater., 2017, 7(18), 1700005.

9 C. Luan, G. Liu, Y. Liu, L. Yu, Y. Wang, Y. Xiao, H. Qiao, X. Dai and X. Zhang, Structure effects of 2D materials on $\alpha$ nickel hydroxide for oxygen evolution reaction, ACS Nano, 2018, 12(4), 3875-3885.

$10 \mathrm{~F}$. Song and X. Hu, Exfoliation of layered double hydroxides for enhanced oxygen evolution catalysis, Nat. Commun., 2014, 5, 4477.

$11 \mathrm{~F}$. Song and X. Hu, Ultrathin cobalt-manganese layered double hydroxide is an efficient oxygen evolution catalyst, J. Am. Chem. Soc., 2014, 136(47), 16481-16484.

12 H. Wang, J. Zhang, X. Hang, X. Zhang, J. Xie, B. Pan and Y. Xie, Half-Metallicity in Single-Layered Manganese Dioxide Nanosheets by Defect Engineering, Angew. Chem., Int. Ed., 2015, 54(4), 1195-1199.

13 W. Liu, H. Liu, L. Dang, H. Zhang, X. Wu, B. Yang, Z. Li, X. Zhang, L. Lei and S. Jin, Amorphous cobalt-iron hydroxide nanosheet electrocatalyst for efficient electrochemical and photo-electrochemical oxygen evolution, Adv. Funct. Mater., 2017, 27(14), 1603904.

14 J. Li, X. Gao, Z. Li, J. H. Wang, L. Zhu, C. Yin, Y. Wang, X. B. Li, Z. Liu and J. Zhang, Superhydrophilic graphdiyne accelerates interfacial mass/electron transportation to boost electrocatalytic and photoelectrocatalytic water oxidation activity, Adv. Funct. Mater., 2019, 29(16), 1808079.

15 V. Vij, S. Sultan, A. M. Harzandi, A. Meena, J. N. Tiwari, W.-G. Lee, T. Yoon and K. S. Kim, Nickel-based electrocatalysts for energy-related applications: oxygen reduction, oxygen evolution, and hydrogen evolution reactions, ACS Catal., 2017, 7(10), 7196-7225.

16 A. Bergmann, T. E. Jones, E. M. Moreno, D. Teschner, P. Chernev, M. Gliech, T. Reier, H. Dau and P. Strasser, Unified structural motifs of the catalytically active state of Co (oxyhydr) oxides during the electrochemical oxygen evolution reaction, Nat. Catal., 2018, 1(9), 711.

17 Y. Hou, M. Qiu, M. G. Kim, P. Liu, G. Nam, T. Zhang, X. Zhuang, B. Yang, J. Cho and M. Chen, Atomically dispersed nickel-nitrogen-sulfur species anchored on porous carbon nanosheets for efficient water oxidation, Nat. Commun., 2019, 10(1), 1392.

18 A. Munir, T. Haq, A. Qurashi, H. Rehman, A. Ul-Hamid and I. Hussain, Ultrasmall Ni/NiO Nanoclusters on ThiolFunctionalized and-Exfoliated Graphene Oxide Nanosheets for Durable Oxygen Evolution Reaction, ACS Appl. Energy Mater., 2018, 2(1), 363-371.

19 R. Ma and T. Sasaki, Nanosheets of oxides and hydroxides: ultimate 2D charge-bearing functional crystallites, $A d v$. Mater., 2010, 22(45), 5082-5104.
20 D. Deng, K. Novoselov, Q. Fu, N. Zheng, Z. Tian and X. Bao, Catalysis with two-dimensional materials and their heterostructures, Nat. Nanotechnol., 2016, 11(3), 218.

21 T. Takashima, K. Hashimoto and R. Nakamura, Mechanisms of pH-dependent activity for water oxidation to molecular oxygen by $\mathrm{MnO} 2$ electrocatalysts, J. Am. Chem. Soc., 2012, 134(3), 1519-1527.

22 O. Diaz-Morales, D. Ferrus-Suspedra and M. T. Koper, The importance of nickel oxyhydroxide deprotonation on its activity towards electrochemical water oxidation, Chem. Sci., 2016, 7(4), 2639-2645.

23 J. E. Post and D. R. Veblen, Crystal structure determinations of synthetic sodium, magnesium, and potassium birnessite using TEM and the Rietveld method, Am. Mineral., 1990, 75(5-6), 477-489.

24 J. C. Conesa, Electronic structure of the (undoped and Fedoped) NiOOH $\mathrm{O} 2$ evolution electrocatalyst, J. Phys. Chem. C, 2016, 120(34), 18999-19010.

25 M. Belli, A. Scafati, A. Bianconi, S. Mobilio, L. Palladino, A. Reale and E. Burattini, X-ray absorption near edge structures (XANES) in simple and complex Mn compounds, Solid State Commun., 1980, 35(4), 355-361.

26 P. Ghigna, G. Flor and G. Spinolo, An Mn-K Edge XAS Investigation on the Crystal Chemistry of Cd1- $\delta \mathrm{Mn} 2 \mathrm{Oy}, J$. Solid State Chem., 2000, 149(2), 252-255.

27 J.-K. Chang, M.-T. Lee and W.-T. Tsai, In situ Mn K-edge X-ray absorption spectroscopic studies of anodically deposited manganese oxide with relevance to supercapacitor applications, J. Power Sources, 2007, 166(2), 590-594.

28 D. Friebel, M. W. Louie, M. Bajdich, K. E. Sanwald, Y. Cai, A. M. Wise, M.-J. Cheng, D. Sokaras, T.-C. Weng and R. Alonso-Mori, Identification of highly active Fe sites in (Ni, Fe) $\mathrm{OOH}$ for electrocatalytic water splitting, J. Am. Chem. Soc., 2015, 137(3), 1305-1313.

29 M. Görlin, P. Chernev, J. Ferreira de Araújo, T. Reier, S. Dresp, B. Paul, R. Krähnert, H. Dau and P. Strasser, Oxygen evolution reaction dynamics, faradaic charge efficiency, and the active metal redox states of $\mathrm{Ni}-\mathrm{Fe}$ oxide water splitting electrocatalysts, J. Am. Chem. Soc., 2016, 138(17), 5603-5614.

30 M. Görlin, J. Ferreira de Araújo, H. Schmies, D. Bernsmeier, S. Dresp, M. Gliech, Z. Jusys, P. Chernev, R. Kraehnert, H. Dau and P. Strasser, Tracking Catalyst Redox States and Reaction Dynamics in Ni-Fe Oxyhydroxide Oxygen Evolution Reaction Electrocatalysts: The Role of Catalyst Support and Electrolyte pH, J. Am. Chem. Soc., 2017, 139(5), 2070-2082.

31 B. S. Yeo and A. T. Bell, In situ Raman study of nickel oxide and gold-supported nickel oxide catalysts for the electrochemical evolution of oxygen, J. Phys. Chem. C, 2012, 116(15), 8394-8400.

32 S. R. Mellsop, A. Gardiner, B. Johannessen and A. T. Marshall, Structure and transformation of oxyhydroxide films on $\mathrm{Ni}$ anodes below and above the oxygen evolution potential in alkaline electrolytes, Electrochim. Acta, 2015, 168, 356-364. 
33 K. Xu, P. Chen, X. Li, Y. Tong, H. Ding, X. Wu, W. Chu, Z. Peng, C. Wu and Y. Xie, Metallic nickel nitride nanosheets realizing enhanced electrochemical water oxidation, J. Am. Chem. Soc., 2015, 137(12), 4119-4125.

34 J. Liu, Y. Zheng, Y. Jiao, Z. Wang, Z. Lu, A. Vasileff and S. Z. Qiao, $\mathrm{NiO}$ as a bifunctional promoter for $\mathrm{RuO} 2$ toward superior overall water splitting, Small, 2018, 14(16), 1704073.

35 C. Stoffelsma, P. Rodriguez, G. Garcia, N. Garcia-Araez, D. Strmcnik, N. M. Marković and M. T. Koper, Promotion of the oxidation of carbon monoxide at stepped platinum single-crystal electrodes in alkaline media by lithium and beryllium cations, J. Am. Chem. Soc., 2010, 132(45), 1612716133.

36 G. García, C. Stoffelsma, P. Rodriguez and M. T. Koper, Influence of beryllium cations on the electrochemical oxidation of methanol on stepped platinum surfaces in alkaline solution, Surf. Sci., 2015, 631, 267-271.

37 J. Suntivich, E. E. Perry, H. A. Gasteiger and Y. Shao-Horn, The Influence of the Cation on the Oxygen Reduction and Evolution Activities of Oxide Surfaces in Alkaline Electrolyte, Electrocatalysis, 2013, 4(1), 49-55.

38 M. Xiao, Y. Tian, Y. Yan, K. Feng and Y. Miao, Electrodeposition of $\mathrm{Ni}(\mathrm{OH}) 2 / \mathrm{NiOOH}$ in the presence of urea for the improved oxygen evolution, Electrochim. Acta, 2015, 164, 196-202.
39 W. Jin, H. Du, S. Zheng, H. Xu and Y. Zhang, Comparison of the oxygen reduction reaction between $\mathrm{NaOH}$ and $\mathrm{KOH}$ solutions on a Pt electrode: the electrolyte-dependent effect, J. Phys. Chem. B, 2010, 114(19), 6542-6548.

40 A. C. Thenuwara, E. B. Cerkez, S. L. Shumlas, N. H. Attanayake, I. G. McKendry, L. Frazer, E. Borguet, Q. Kang, R. C. Remsing, M. L. Klein, M. J. Zdilla and D. R. Strongin, Angew. Chem., Int. Ed., 2016, 55(35), 1038110385.

41 T. Nakagawa, C. A. Beasley and R. W. Murray, Efficient electro-oxidation of water near its reversible potential by a mesoporous IrO x nanoparticle film, J. Phys. Chem. C, 2009, 113(30), 12958-12961.

42 J. Y. Chen, J. T. Miller, J. B. Gerken and S. S. Stahl, Inverse spinel NiFeAlO 4 as a highly active oxygen evolution electrocatalyst: promotion of activity by a redox-inert metal ion, Energy Environ. Sci., 2014, 7(4), 1382-1386.

43 K. Fan, H. Chen, Y. Ji, H. Huang, P. M. Claesson, Q. Daniel, B. Philippe, H. Rensmo, F. Li, Y. Luo and L. Sun, Nickelvanadium monolayer double hydroxide for efficient electrochemical water oxidation, Nat. Commun., 2016, 7(1), 11981.

44 J. Zhang, J. Liu, L. Xi, Y. Yu, N. Chen, S. Sun, W. Wang, K. M. Lange and B. Zhang, Single-Atom Au/NiFe Layered Double Hydroxide Electrocatalyst: Probing the Origin of Activity for Oxygen Evolution Reaction, J. Am. Chem. Soc., 2018, 140(11), 3876-3879. 